\title{
Perencanaan Ulang Struktur Atas Bangunan Kantor Dinas Pangan Provinsi Sumatera Barat
}

\author{
Frengki Jasmanto ${ }^{1}$ Afrilda Sari ${ }^{2}$ Rafki Imani ${ }^{3}$ \\ ${ }^{1}$ Universitas Putra Indonesia "YPTK" Padang, Indonesia
}

Email: Frengkijasmanto@gmail.com

\begin{abstract}
Upper structure is a building structure that is above the ground level such as columns, beams and floor plates. Each of these components has a different function in a structure. The reason for the appointment of this title is because the dimensions and use of reinforcement in this structure are inefficient and too wasteful. Therefore this title was appointed as a case study with the aim of planning the dimensions and structural reinforcement consisting of column elements, beams and floor plates in an efficient Padang city food office building and reviewing the structural design due to the use of reinforcement and dimensions too over or wasteful. . The method used in dimensioning and calculating reinforcement uses the SAP 2000 v14 method. With a design load that includes dead load, live load, and earthquake load in accordance with SNI 1727-2013 regarding the minimum load for planning buildings and other structures. Overall, the construction structure of this building is quite complex to discuss due to the additional roof load in the form of a helipad. From the results of this discussion, dimensions and structural reinforcement are more efficient and reduce construction costs, without reducing the quality and function they should be..
\end{abstract}

Keywords: Upper Structure, Plan Load, SNI 1727-2013, Helipad.

\begin{abstract}
Abstrak
Struktur atas adalah struktur bangunan yang ada di atas permukaan tanah seperti kolom, balok dan pelat lantai. Setiap komponen tersebut memiliki fungsi yang berbeda-beda di dalam sebuah struktur. Alasan diangkatnya judul ini adalah dikarenakan pendimensian serta penggunaan tulangan pada struktur ini tidak efisien dan terlalu boros. Maka dari itu diangkatlah judul ini sebagai studi kasus dengan tujuan merencanakan dimensi dan tulangan struktur atas terdiri dari elemen kolom, balok dan plat lantai pada bangunan kantor pangan kota padang yang efisien dan mereview kembali desain struktur dikarenakan struktur tersebut penggunaan tulangan serta dimensi terlalu over atau boros. Metode yang digunakan dalam pendimensi dan menghitung tulangan dengan menggunakan metode SAP 2000 v14. Dengan beban rencana yang meliputi beban mati, beban hidup, dan beban gempa sesuai dengan SNI 1727-2013 tentang beban minimum untuk perencanaan bangunan gedung dan struktur lain. Secara keseluruhan, struktur konstruksi bangunan ini cukup komplek untuk dibahas dikarenakan adanya beban atap tambahan berupa helipad. Dari hasil pembahasan ini adalah dimensi serta penulangan struktur yang lebih efisien dan mengurangi biaya konstruksi, tanpa mengurangi kualitas dan fungsi yang seharusnya.
\end{abstract}

Kata kunci: Struktur Atas, Beban Rencana, SNI 1727-2013, Helipad.

\section{Pendahuluan}

Ketahanan pangan adalah salah satu isu strategis dalam pembangunan suatu Negara. Untuk mewujudkan ketahanan pangan, sektor pertanian merupakan sektor yang sangant penting karena sektor ini menjadi penyedia pangan utama, lebih-lebih negara yang sedang berkembang, karena memiliki peran ganda yaitu sebagai salah satu sasaran utama pembangunan dan dan salah satu instrument utama pembangunan ekonomi. Saat ini, kantor pangan kota padang merupakan salah satu kantor terdepan di kota padang. Demi menunjang kebutuhan pangan dan mengontrol kenaikan dan penurunan harga pangan, walikota padang mengembangkan fasilitasnya dengan membangun bangunan kantor pangan baru berkonstruksi beton bertulang yang memiliki fasilitas helipad pada atapnya. Fasilitas helipad ini merupakan pertama dan satu-satunya fasilitas transportasi udara untuk kantor di kota Padang. Sehingga, apabila ada kesalahan ataupun gangguan transporati lewat darat ataupun lewat laut sekalian, maka fasilitas ini sangat membantu pemerintah untuk mengontrol dan mempermudah pemerintah ataupun mentri-mentri baik itu mentri dalam negri maupun mentri luar negri. Tidak hanya itu, fungsi lantai atas dari kantor ini juga berfungsi sebagai selter bencana tsunami untuk masyarakat kota, semua itu di karenakan letak kantor pangan ini sangat dekat dengan bibir pantai. Tidak hanya itu fungsi lainnya untuk mengangkut dan menyelamatkan dokument rahasia milik negara apabila terjadinya gejolak atau peperangan dikota padang. Secara keseluruhan, struktur dari konstruksi bangunan kantor pangan cukup kompleks untuk dibahas. Pada struktur bawah, bangunan ini menggunakan konstruksi pondasi dalam berupa tiang pancang untuk menunjang beban dari struktur atas bangunan ini. Untuk struktur atas, terdapat struktur kolom, balok, dan plat lantai yang berkonstruksi

Diterima Redaksi : 16-10-2020 | Selesai Revisi :27-10-2020 | Diterbitkan Online : 31-10-2020 
struktur beton bertulang, termasuk helipad pada atapnya. Dari hal inilah, maka akan dibahas mengenai perencanaan ulang konstruksi struktur atas "KANTOR DINAS KETAHANAN PANGAN PROVINSI SUMATERA BARAT" yang merupakan struktur pokok pada konstruksi sebuah bangunan

\section{Metode Penelitian}

Struktur bangunan yang digunakan adalah struktur portal tiga lantai. Pembebanan yang digunakan dalam penelitian ini meliputi beban mati, beban hidup, dan beban gempa. Data-data yang ada tersebut kemudian akan diinput dan dianalisis lebih lanjut menggunakan bantuan program SAP2000 V14. Dapat dilihat pada gambar 1.

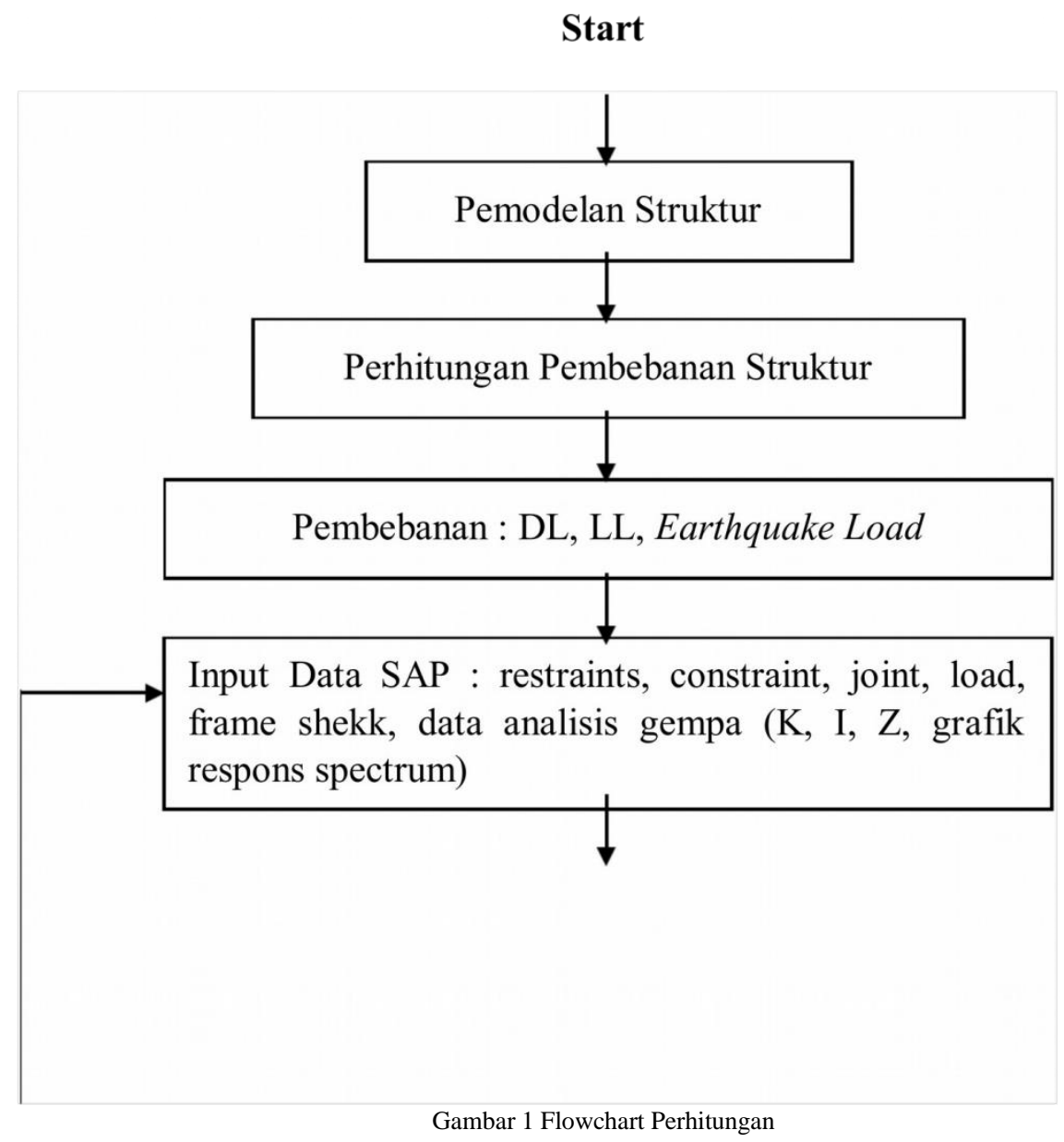

2.1. Panjang Naskah (sub judul tidak cetak tebal)

Naskah ditulis dalam ukuran kertas A4 dengan jumlah halaman minimum 6 halaman, maksimum 10 halaman, termasuk tabel dan gambar, serta dengan mengacu tata cara penulisan seperti telah yang disusun pada tulisan ini.

Rumus ditulis secara jelas menggunakan equation dengan indeks seperti rumus 1.

$$
\Delta F=-2,3 \times 10^{6} \times F^{2} \frac{\Delta M}{A}
$$

\subsection{Organisasi Naskah}

Judul harus jelas dan singkat, maksimal 12 kata, ukuran huruf 15pt, tidak cetak tebal dan hanya huruf awal kata saja yang dicetak kapital. Nama penulis dan afiliasinya seperti yang tertulis diatas. Nama penulis ditulis secara jelas tanpa gelar. Penomoran heading dengan sistem Arabic dengan sub-heading maksimal hingga 3 tingkat.

\subsection{Tabel}

Tabel harus diberi nomor sesuai urutan presentasi (Tabel 1, dst.). Judul tabel ditulis diatas tabel dengan posisi rata tengah (center justified), tidak ada cetak tebal maupun berwarna. Font yang dipakai berukuran 8pt baik judul tabel maupun isi tabel. Tabel harus diacu dan dirujuk dalam text. 
Tabel 1.Tabel Mata Uang di Berbagai Negara

\begin{tabular}{llll}
\hline & Negara & Ibukota & Mata Uang \\
\hline Indonesia & Jakarta & Rupiah \\
\hline Malaysia & Kuala Lumpur & Ringgit \\
\hline Thailand & Bangkok & Bath \\
\hline
\end{tabular}

\section{Hasil dan Pembahasan}

Gedung yang direncanakan ulang adalah Kantor Dinas Pangan Provinsi Sumatera Barat yang merupakan gedung beton bertulang tiga lantai. Perencanaan ulang ini dilakukan karena pada elemen kolom dan balok terjadi pemborosan penggunaan baik itu dimensi dan penggunaan tulangan, mka dari itu diangkatlah studi kasus ini. Pada reviuw desain kali ini Cuma terfokus kepada kolom, balok dan pelat lantai.

Tampak depan dan tampak samping gedung Kantor Dinas Pangan Provinsi Sumatera Barat ditunjukkan dalam gambar 2 dan gambar 3, untuk denah kolom dan detail kolom lantai satu ditunjukan pada gambar 4, 5 dan gambar 6.

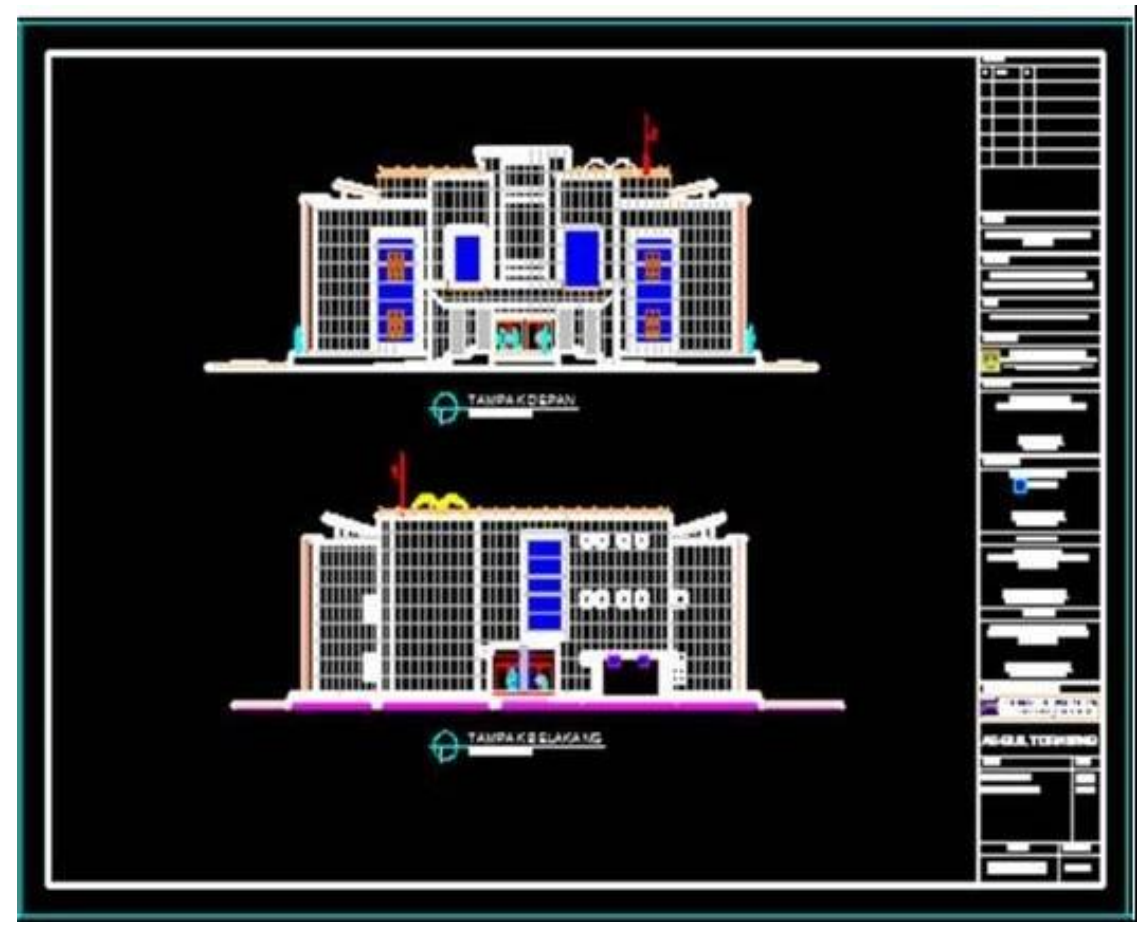

Gambar 2 Tampak Depan dan Belakang 


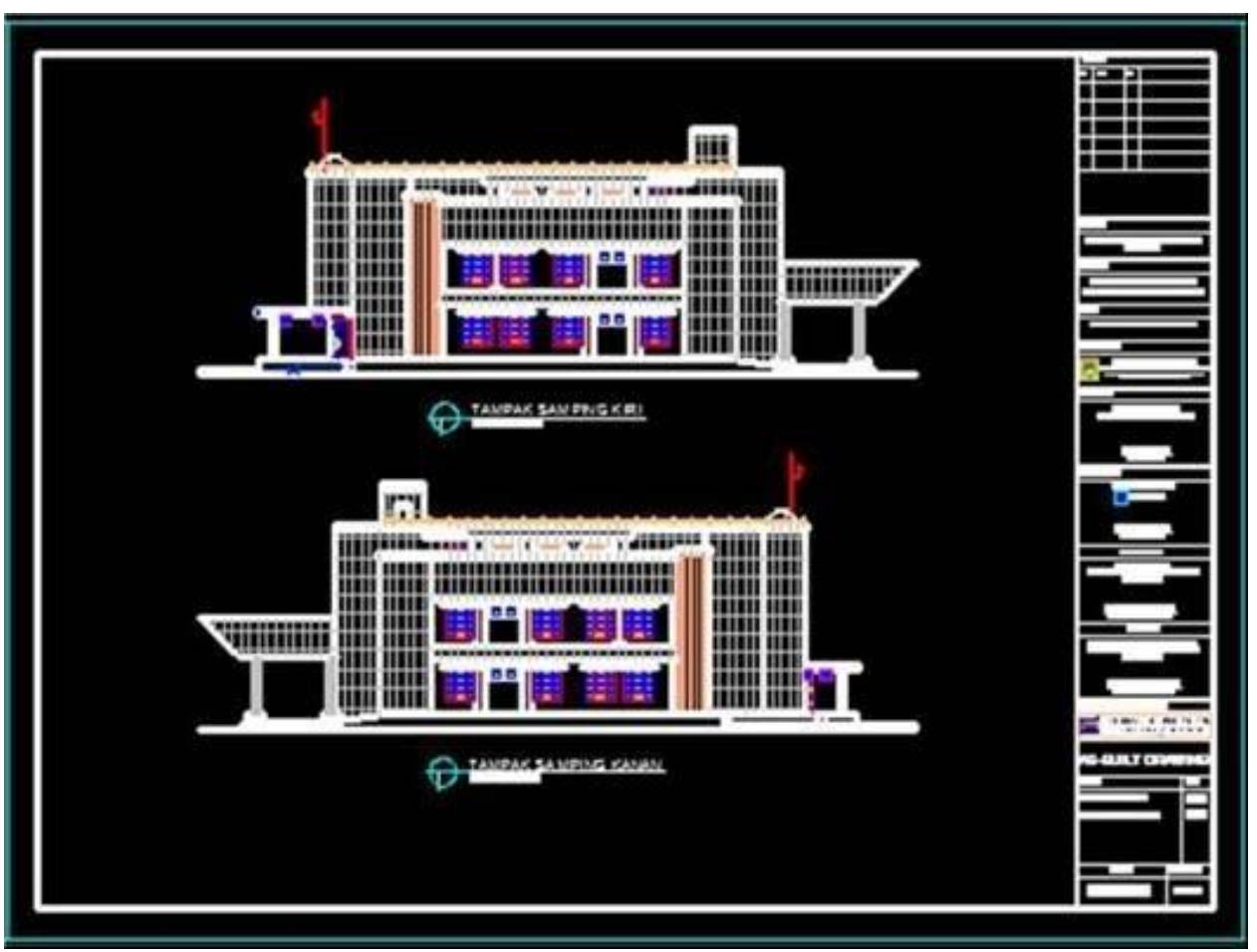

Gambar 3 Tampak Samping

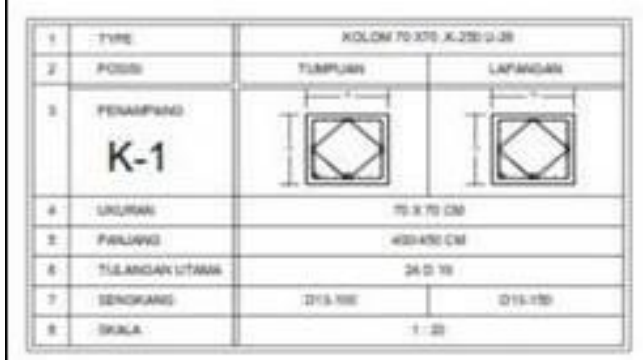

\begin{tabular}{|c|c|c|c|}
\hline F & $\sin$ & \multicolumn{2}{|c|}{ rasowerexasual } \\
\hline$x$ & pons & nomens & nomena \\
\hline \multirow[t]{2}{*}{$\mathrm{x}$} & neversese & $\Leftrightarrow-$ & $\because-$ \\
\hline & $\mathrm{K}-2$ & I[G] & [L]] \\
\hline . & wasken & \multicolumn{2}{|c|}{ Exara } \\
\hline , & ranieses & \multicolumn{2}{|c|}{ wascu } \\
\hline$\cdot$ & Remsenviswen & \multicolumn{2}{|c|}{400} \\
\hline$t$ & anowes & Diso & nis: \\
\hline e & 30 & \multicolumn{2}{|c|}{$x \neq$} \\
\hline
\end{tabular}

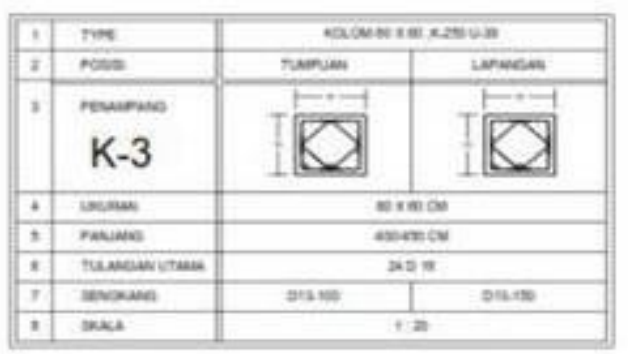

\begin{tabular}{|c|c|c|c|}
\hline i & $m$ & \multicolumn{2}{|c|}{ 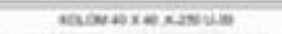 } \\
\hline 2 & mans & nownen & Lanciens \\
\hline \multirow[t]{2}{*}{ 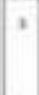 } & roweresos & $t+1$ & $m+1$ \\
\hline & $K-4$ & 10 & $\square$ \\
\hline . & men & \multicolumn{2}{|c|}{ nima } \\
\hline , & Panive & \multicolumn{2}{|c|}{ estew } \\
\hline . & rumsenvent & \multicolumn{2}{|c|}{800} \\
\hline , & novens & sone & 0010 \\
\hline . & sect & \multicolumn{2}{|c|}{$x:=$} \\
\hline
\end{tabular}

Gambar 4 Detail Kolom 
Frengki Jasmanto, Afrilda Sari, Rafki Imani

Jurnal Teknologi Vol 10 No 2 (2020 ) 7-14

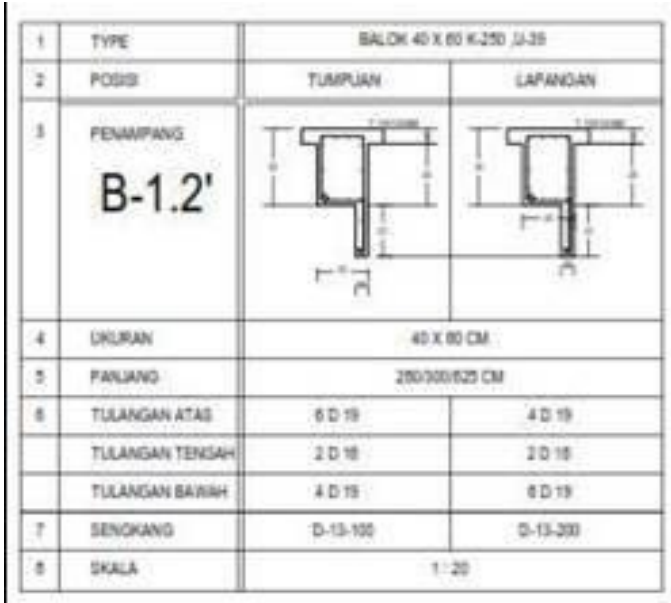

\begin{tabular}{|c|c|c|c|}
\hline 1 & TrEe & \multicolumn{2}{|c|}{ 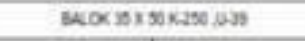 } \\
\hline$z$ & noes & Trurias & LAPACLAN \\
\hline 1 & B-1.3' & & + \\
\hline 4 & GoNAN & \multicolumn{2}{|c|}{$20 \times 900 \mathrm{cu}$} \\
\hline , & FWuens & \multicolumn{2}{|c|}{ zovosearnocu } \\
\hline \multirow[t]{3}{*}{ 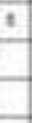 } & Tulascasiotes & 10015 & 9013 \\
\hline & Theveds revant & 200 & 20 is \\
\hline & TLANCANBaLAH & 1013 & 7019 \\
\hline 1 & serosenes & $\sin x$ & $0.03 x+1$ \\
\hline$t$ & seen & \multicolumn{2}{|c|}{$t x$} \\
\hline
\end{tabular}

\begin{tabular}{|c|c|c|c|}
\hline 1 & $\pi$ & \multicolumn{2}{|c|}{ 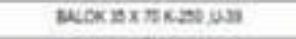 } \\
\hline 2 & nots & nernes & upinow \\
\hline 3 & B-1.1. & $+\frac{\pi}{4}$ & $\prod_{1} \frac{1}{2}$ \\
\hline 4 & bunw & \multicolumn{2}{|c|}{$35 \times 70 \mathrm{cu}$} \\
\hline 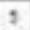 & navevo & \multicolumn{2}{|c|}{ costzan } \\
\hline 5 & Raboven atas & 10018 & 9013 \\
\hline & Thaseas troded & 2010 & $20 x$ \\
\hline & Tudivowsuant & 980 & $85 n$ \\
\hline 7 & sevoreve & Dis: $x$ & 0.90300 \\
\hline 1 & sen & \multicolumn{2}{|c|}{$1: 20$} \\
\hline
\end{tabular}

Gambar 5 Detail Balok 1

\begin{tabular}{|c|c|c|c|}
\hline 9 & $\operatorname{TT}$ & \multicolumn{2}{|c|}{$v 0 \times 40 \times 10 \times 230,030$} \\
\hline 2 & poses & nervar & wowow \\
\hline \multirow[t]{2}{*}{3} & pesuenswo & Gका & Gक्य \\
\hline & & $+\infty-1$ & $F=-1$ \\
\hline 4 & Solmex & \multicolumn{2}{|c|}{$4 \times 150 \mathrm{Cu}$} \\
\hline 3 & nesureso & \multicolumn{2}{|c|}{ xotesinacu } \\
\hline \multirow{3}{*}{1} & Teunsesiatial & $10=$ & $30 \%$ \\
\hline & Funser towcen & $20 \%$ & $20=$ \\
\hline & 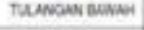 & 100 & $70=$ \\
\hline 7 & sencowas & $D+2-10$ & Doses \\
\hline 1 & souk & \multicolumn{2}{|c|}{$t x$} \\
\hline
\end{tabular}

\begin{tabular}{|c|c|c|c|}
\hline i & Tax & \multicolumn{2}{|c|}{ 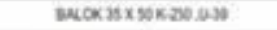 } \\
\hline 2 & Forea & nusouw & Lapacion. \\
\hline \multirow[t]{2}{*}{3} & RUASTNO & 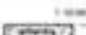 & 5 \\
\hline & & 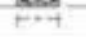 & 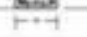 \\
\hline - & Worew & \multicolumn{2}{|c|}{ 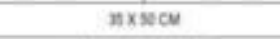 } \\
\hline 1 & REvane & \multicolumn{2}{|c|}{ sooseserinzicu } \\
\hline \multirow[t]{3}{*}{4} & Rewcies athe & 1010 & 725 \\
\hline & reuwoen tevcen & $20=$ & $201 \mathrm{E}$ \\
\hline & rewows maxn & $30 \mathrm{n}$ & $30 \pi$ \\
\hline I & SENGWWO & 2.136 & and \\
\hline 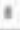 & sous & \multicolumn{2}{|c|}{$1: 20$} \\
\hline
\end{tabular}

Gambar 6 Detail Balok 3 


\begin{tabular}{|c|c|c|c|c|c|c|}
\hline Type & Dimensi & Momen & Gaya & Tulangan & Tulangan & Tulangan \\
& $(\mathrm{Cm})$ & $(\mathrm{kN} . \mathrm{m})$ & Aksial & Utama & Sengkang & Sengkang \\
& & & $(\mathrm{kN} . \mathrm{m})$ & & Tumpuan & Lapangan \\
\hline $\mathrm{K}-1$ & $50 \times 50$ & 753,5237 & 276,368 & $20 \mathrm{D} 19$ & $\mathrm{D} 13-100$ & $\mathrm{D} 13-100$ \\
\hline $\mathrm{K}-2$ & $30 \times 50$ & 363,924 & 131,679 & $20 \mathrm{D} 16$ & $\mathrm{D} 13-150$ & $\mathrm{D} 13-150$ \\
\hline $\mathrm{K}-3$ & $40 \times 40$ & 142,0756 & 69,157 & $20 \mathrm{D} 16$ & $\mathrm{D} 13-200$ & $\mathrm{D} 13-200$ \\
& & & & & & \\
\hline $\mathrm{K}-4$ & $40 \times 40$ & 219,842 & 101,462 & $16 \mathrm{D} 16$ & $\mathrm{D} 13-150$ & $\mathrm{D} 13-150$ \\
& & & & & & \\
\hline
\end{tabular}

Tabel 2 Hasil Perhitungan Penulangan dan Dimensi Balok

\begin{tabular}{|c|c|c|c|c|c|c|c|}
\hline $\begin{array}{c}\text { Type } \\
\text { Balok }\end{array}$ & $\begin{array}{c}\text { Dimensi } \\
(\mathrm{Cm})\end{array}$ & Area & $\begin{array}{l}\text { Momen } \\
(\mathrm{kN} . \mathrm{m})\end{array}$ & $\begin{array}{l}\text { Gaya } \\
\text { Aksial } \\
\text { (kN.m) }\end{array}$ & $\begin{array}{c}\text { Tulangan } \\
\text { Utama } \\
\text { Atas }\end{array}$ & $\begin{array}{c}\text { Tulangan } \\
\text { Utama } \\
\text { Bawah }\end{array}$ & $\begin{array}{l}\text { Tulangan } \\
\text { Sengkang }\end{array}$ \\
\hline B-1.1 & $35 \times 65$ & Tumpuan & 457,583 & 430,1 & $11 \mathrm{D} 19$ & 6 D19 & D13-100 \\
\hline & & Lapangan & 370,564 & 390,127 & $4 \mathrm{D} 19$ & $8 \mathrm{D} 19$ & D13-150 \\
\hline B-1.2 & $30 \times 55$ & Tumpuan & 186,417 & 148,555 & $8 \mathrm{D} 16$ & $5 \mathrm{D} 16$ & D13-150 \\
\hline & & Lapangan & 141,192 & 143,545 & 4D16 & $6 \mathrm{D} 16$ & D13-200 \\
\hline B-1.3 & $30 \times 55$ & Tumpuan & 205,836 & 144,051 & $\overline{9 D 19}$ & $5 \mathrm{D} 19$ & D13-150 \\
\hline
\end{tabular}




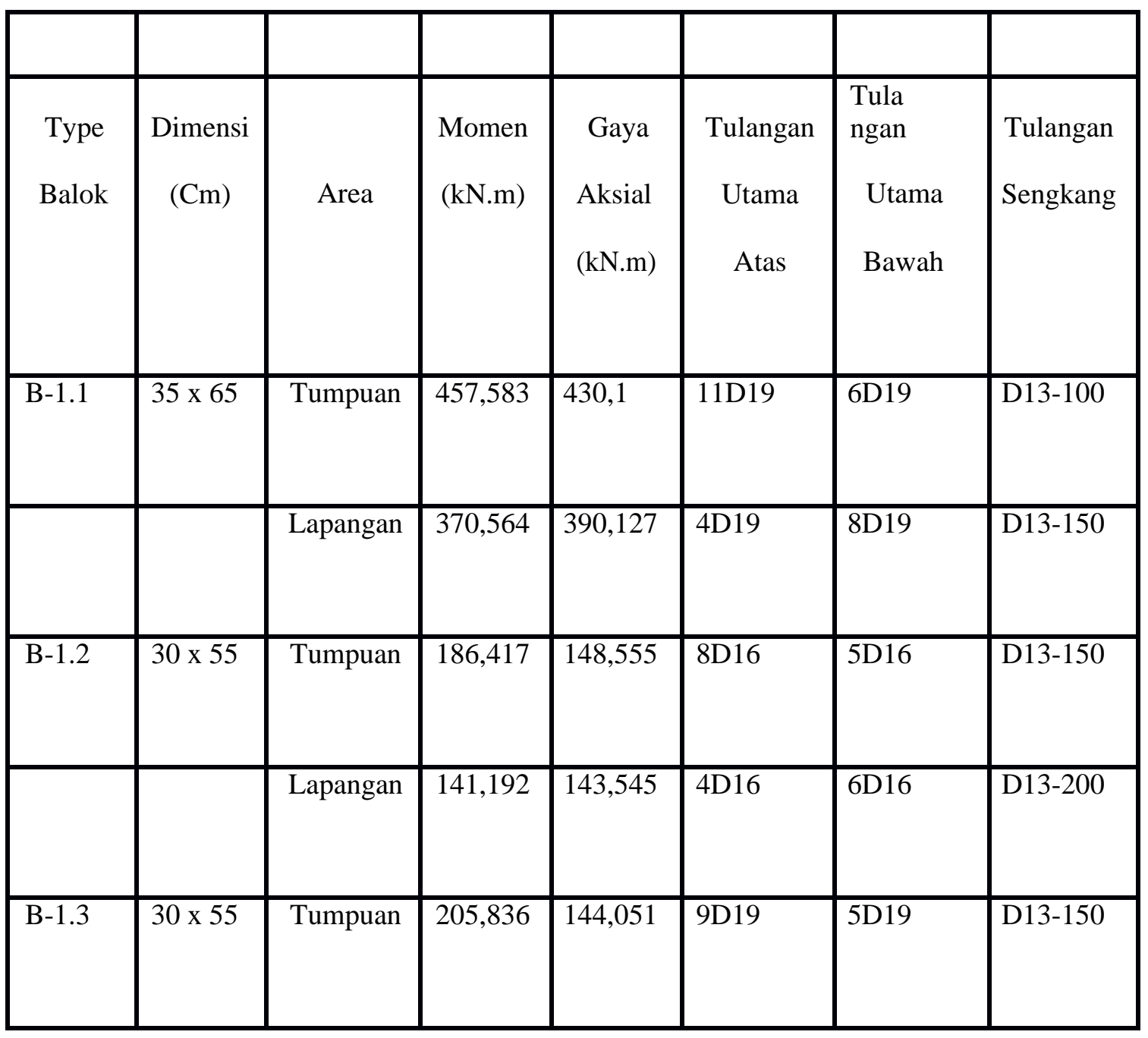

Tabel 3 Hasil Perhitungan Penulangan dan Dimensi pelat

\begin{tabular}{|c|c|c|c|c|}
\hline Type & Dimensi & Momen & Tulangan & Tulangan \\
Pelat & $(\mathrm{mm})$ & $(\mathrm{kN.m})$ & Arah & Bagi \\
& & & X dan Y & \\
\hline Pelat Lantai & 120 & 25,135 & D12-200 & D12-100 \\
\hline Pelat Dak & 120 & 16,5842 & D12-200 & \\
\hline Pelat Helipad & 150 & 51,6007 & D12-150 & D12-100 \\
\hline
\end{tabular}




\section{Kesimpulan}

Dari uraian serta pembahasan yang telah disajikan pada bab-bab sebelumnya, setelah melakukan analisis pada struktur bangunan gedung kantor dinas pangan, maka dapat ditarik beberapa kesimpulan, yaitu sebagai berikut :

1. Dari hasil analisa yang telah dilakukan dan dilakukannya perbandingan maka dapat diambil kesimpulan bahwa penulangan dan dimensi pada kolom dan balok terjadi kelebihan (over) penggunaan untuk semua balok dan kolom yang sebelumnya telah direncanakan.

2. Untuk penulangan serta dimensi pelat lantai, pelat dak dan pelat helipad bisa digunakan karena pelat tersebut penggunaannya normal.

3. Dari 18 kombinasi yang diterapkan pada pemodelan struktur ini, maka secara garis besar kombinasi yang paling berpengaruh pada struktur ini adalah kombinasi 3 karena adanya beban hidup tambahan berupa beban helikopter sebesar 2,87 ton.

\section{Daftar Rujukan}

[1] Yuhefizar, Santosa B., Eddy I. K. P, and Suprapto Y. K, 2013, Combination of Cluster Method for Segmentation of Web Visitors. TELKOMNIKA, 11(1), pp. 207-214. doi: http://dx.doi.org/10.12928/telkomnika.v11i1.906.

[2] Na`am J., Harlan J., Madenda S., and Wibowo E. P. 2016. Identification of the Proximal Caries of Dental X-Ray Image with Multiple Morphology Gradient Method. International Journal on Advanced Science, Engineering and Information Technology (IJASEIT), 6(3), pp. 343-346. doi:10.18517/ijaseit.6.3.827.

[3] Na`am J., 2017. Edge Detection on Objects of Medical Image with Enhancement multiple Morphological Gradient (EmMG) Method. 4th Proc. EECSI. 23-24 Sep. 2017. Yogyakarta: Indonesia. doi=10.1109/EECSI.2017.8239085 
